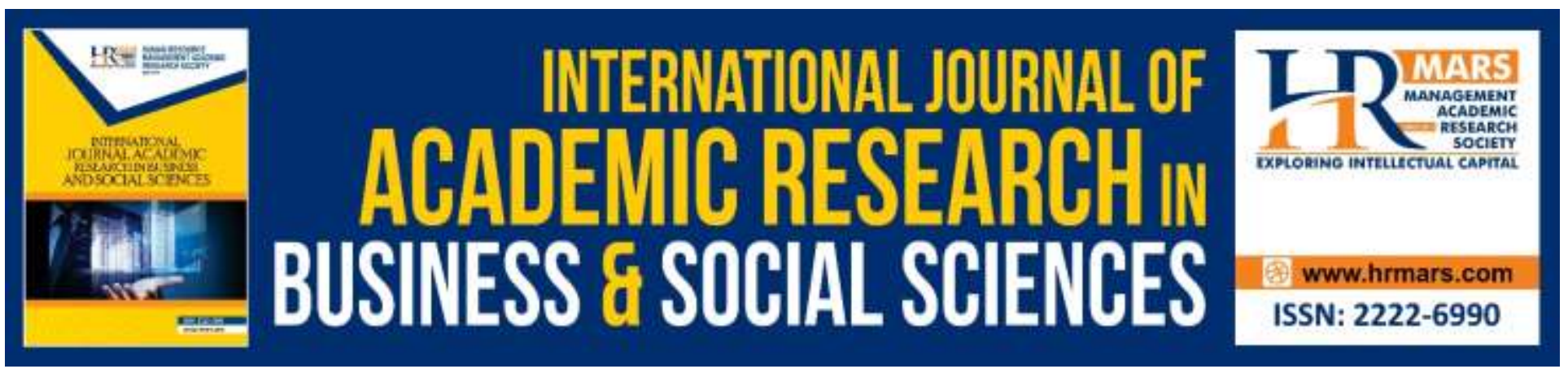

\title{
Enhancing ESL Writing using Sentence Variety Checklist
}

\author{
Liza Abdullah, Rosnani Kassim, Noor Amili Abdul Ghani, Hazlinah Ab \\ Rahman \& Ainul Azmin Md Zamin
}

To Link this Article: http://dx.doi.org/10.6007/IJARBSS/v9-i13/6245

DOI: $10.6007 /$ IJARBSS/v9-i13/6245

Received: 21 March 2019, Revised: 09 July 2019, Accepted: 29 July 2019

Published Online: 23 August 2019

In-Text Citation: (Abdullah, Kassim, Ghani, Rahman, \& Zamin, 2019)

To Cite this Article: Abdullah, L., Kassim, R., Ghani, N. A. A., Rahman, H. A., \& Zamin, A. A. M. (2019). Enhancing ESL Writing Using Sentence Variety Checklist. International Journal of Academic Research in Business and Social Sciences, 9(13), 87-95.

Copyright: (C) 2019 The Author(s)

Published by Human Resource Management Academic Research Society (www.hrmars.com)

This article is published under the Creative Commons Attribution (CC BY 4.0) license. Anyone may reproduce, distribute, translate and create derivative works of this article (for both commercial and non-commercial purposes), subject to full attribution to the original publication and authors. The full terms of this license may be seen

at: $\underline{\text { http://creativecommons.org/licences/by/4.0/legalcode }}$

Special Issue: Revolutionizing Education: Challenges, Innovation, Collaboration, 2019, Pg. 87 - 95

http://hrmars.com/index.php/pages/detail/IJARBSS

JOURNAL HOMEPAGE

Full Terms \& Conditions of access and use can be found at http://hrmars.com/index.php/pages/detail/publication-ethics 


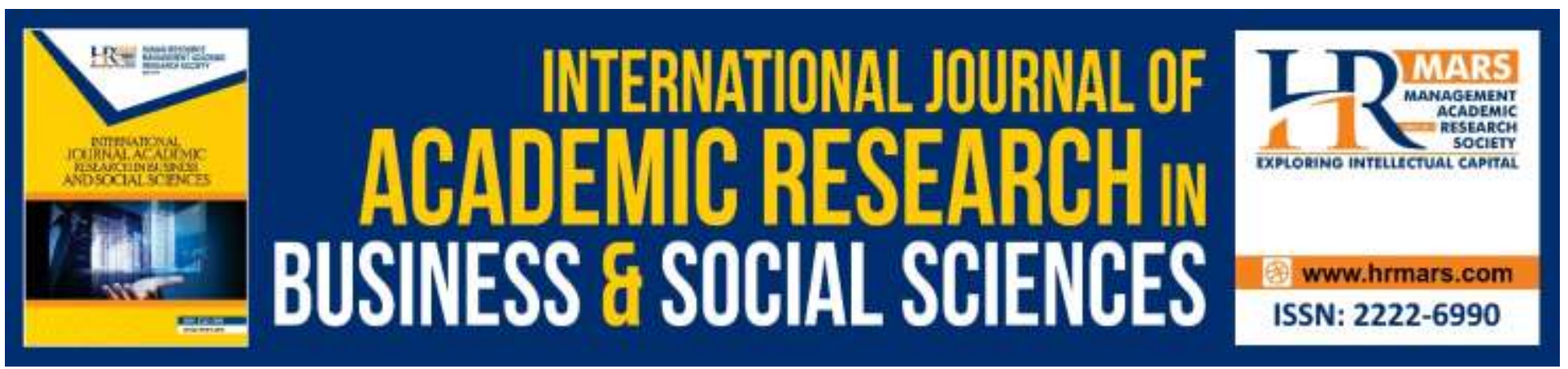

\title{
Enhancing ESL Writing Using Sentence Variety Checklist
}

\author{
Liza Abdullah, Rosnani Kassim, Noor Amili Abdul Ghani, Hazlinah \\ Ab Rahman \& Ainul Azmin Md Zamin \\ International Islamic University Malaysia, Gombak, Selangor, Malaysia \\ Email: liza_abdullah@iium.edu.my
}

\begin{abstract}
Sentence variety is a fundamental aspect in writing to avoid stereotypes, thus making writing more interesting. However, ESL students are often found not using the different sentence structures in writing. Students seem to learn one basic pattern and stick to it. The reason could be due to lack of knowledge and practice to write a variety of sentence structures. They seem to be reluctant to learn more about it, and teachers are reluctant to teach. Despite being fundamental, little emphasis has been put on sentence variety in the ESL Writing classes because most of the time teachers and students think that as long as there are no grammatical errors, the writing is acceptable. Even with improvement, most of them may not really achieve encouraging results in writing. Hence, this study intended to examine the respondents' writing performance before and after using a sentence variety checklist, and to analyse the respondents' perceptions towards using the sentence variety checklist in their writing. Twenty university students from a pre-sessional English Language programme were selected to take part in this study and data were collected qualitatively from students' essays and their responses from a 20 -item survey questionnaire. The findings revealed a slight improvement in students' writing. They also found the checklist made writing more interesting and made the students more aware of what they were writing. In conclusion, sentence variety checklist can be one of the tools for ESL students to boost students' writing performance.
\end{abstract}

Keywords: EsI Writing, Sentence Variety Checklist, Sentence Structures, Sentence Combining

\section{Introduction}

"Writing today is not a frill for the few, but an essential skill for the many" (National Commission on Writing, 2003, p.1). Regardless of disciplines, students of any higher education institutions need to be highly competent at writing for an academic audience. Writing, as perceived by many is a lonely process that requires one to explore, oppose, and make connections between propositions for themselves which eventually must be made clear to whoever the audience is. As a result, in writing, meanings must be explicit, ordered and well-organized. The process of organizing and ordering these 
thoughts must also be accompanied by a clear delivery which involves the 'vehicle' itself, that is the language used in writing, which in this case is the English Language for ESL students.

Saddler (2007) stated that in the U.S, writing is increasingly being evaluated by state and national tests as well as by the college entrance examinations administered by the College Board, and the scores reveal deficits at all grade levels. He further emphasized that instruction is getting more attention in general, but inadequate emphasis is given to the critical skills of generating better sentences. Dankoski et al. (2012) also claimed that for some reasons, writing has developed a negative connotation for many school students because students do not know how to tackle the writing assignments with a sense of confidence. Despite having had the opportunity to write many essays by the time they reach the tertiary level, ESL students generally have not reached a required level of confidence in writing.

Complacency in writing using the only sentence patterns they know makes students keep using the same patterns in writing. In fact, a big number of them may prefer to 'play safe' by using simple sentences in their writing possibly because they had been trained to write as such to avoid making a lot of errors. As a result, they may not be keen on writing various sentences using different structures. Lack of sentence variety is certainly not the only problem faced by ESL students, but to add to this predicament, they also lack native speakers' intuition about what sounds right, and they may just be unaware of the monotonous nature of their writing. Despite knowing that this is a fundamental problem in their writing, students seem to be reluctant to learn more about it. Moreover, teachers are reluctant to teach, because it is so mundane and most of the time both parties think that as long as there are no grammatical errors in writing, it is acceptable. Saddler (2007) elaborated that sentences are the basic elements of written language. Unfortunately, teaching students how to construct good or varied sentences is given too little attention in most classrooms which results in little emphasis given to the significance of sentence variety in ESL writing classrooms.

Numerous researches have been conducted related to this study, nevertheless, most of them are on sentence combining that is the basis of sentence variety. Even though it is considered as the basic elements of written language, constructing good and varied sentences has not been given enough attention in most classrooms which leads to limited research carried out to examine the possible effect of sentence variety on ESL writing performance.

Therefore, this study intended to utilize sentence variety checklist as an intervention for students to use in their writing. The sentence variety checklist used is based on Langan's (1993) framework of sentence variety as shown in Table 1 (Appendix 1). This study may give insight to the importance of emphasising sentence varieties in students' writing to avoid sentences of similar structure and length which can appear monotonous for readers. In fact, varying sentence styles and structures can also reduce repetition and add emphasis. Long sentences work well for incorporating a lot of information, and short sentences can often maximize crucial points (Clabough, 2014). Hence, this study seeks to answer the following research questions: 1 ) Is there any difference in students' writing performance before and after using the sentence variety checklist? 2) What are students' perceptions towards the use of sentence variety checklist in writing?

\section{Literature Review}

The development of ESL writing is very complicated (Congjun, 2005). One of the many aspects stressed upon in improving ESL writing is by putting more emphasis on how to vary their sentence 
structures. Having different sentence patterns in one's writing will make the writing more appealing to the readers in which it is claimed to be able to 'sweeten up' their writing. In addition, according to Scott and Nelson (2009), generating sentences is a necessary part of writing, and the use of more varied and complex sentence structures can be both assessed and supported with activities such as sentence combining.

The Acquisition-Learning hypothesis (Krashen, 1985) emphasized the term 'language acquisition' and 'language learning'. The first is defined as a subconscious process which is claimed to have similarities with the process of acquiring first language among children. This hypothesis focuses on language acquisition that is on meaningful interaction in the target language as well as natural communication with the concentration on the communicative act and not on forms. Language learning, however, is the product of formal instruction and encompasses a conscious process which results in conscious knowledge about the language. Some examples are the knowledge of organizing ideas and thoughts, following grammar rules, choosing the right words, and producing varieties of sentences. This hypothesis suggests that ESL students have to be made aware of the ways to write better using all the learned forms. Moreover, this awareness will make them more conscious about how to improve their writing.

Monitoring their own writing is crucial to ensure students are applying what they are learning. Krashen's Monitor hypothesis seeks to explain how the acquisition affects learning. In the case of initiating communication, second language learners should monitor their utterances, for instance, by utilizing their understanding of learned grammar to edit and plan. This however, according to Krashen, can only occur when speakers have sufficient time to process the form and structure of their sentences in their subconscious minds.

Meanwhile, Silva (1990) roughly divided ESL writing instruction into four stages marked by the four most influential approaches: the controlled approach; the current-traditional-rhetoric approach; the process approach and the social approach. The first approach which is the controlled approach is nevertheless the most relevant theory to this current study for writing is dominated by the controlled or guided approach which is influenced by structural analysis and behaviourist psychology. This approach sees learning to write as an exercise in habit formation in which students are trained to practice sentence patterns and vocabulary by means of writing.

As much as some researchers want to look at studies conducted on sentence variety in English writing, yet, it is to no avail as the topic itself may not be of interest to many ESL writing scholars. The same goes to the area of sentence combining as stated by Saddler (2007). It is important to note that in spite of strong research evidence that shows the effectiveness of sentence combining, it is still not widely covered in many writing workshop approaches. Scott and Nelson (2009) suggested that generating sentences is a necessary part of writing at the text level, and the use of more varied and complex sentence structures can be both assessed and supported with activities such as sentence combining. This notion was supported by Pedersen (1977) when he affirmed that experiences in sentence-combining is associated with extra meaning and variety in students' essays. He discovered that the subjects of the study that engaged in the extended practice in sentence combining did achieve and sustain growth in syntactic fluency and managed to obtain better judged overall quality of writing.

Scott and Balthazar (2013) who focused on the roles of sentences and grammar found that despite the encouraging attention given to sentences, less attention was given to translate this 
INTERNATIONAL JOURNAL OF ACADEMIC RESEARCH IN BUSINESS AND SOCIAL SCIENCES

Vol. 9, No. 13, Special Issue: Revolutionizing Education: Challenges, Innovation, Collaboration., 2019, E-ISSN: 2222-6990 @ 2019 HRMARS

information into principles and practices that influence what educators, clinicians, and special educators actually do. The areas which are lacking in focus were mainly syntax and sentences in which the researchers are attempting to highlight in their study.

\section{Methodology}

A total of 20 students in the intensive English language program in the International Islamic University Malaysia were chosen to participate in this research. They were from one class of upper intermediate level of English proficiency who had undergone 7 out of 14 weeks of intensive English classes. The rationale for choosing this group was mainly because these students did not have a lot of difficulties in writing when it comes to grammar, word choice and sentence structures but the tendency to 'play safe' by writing common structures was always there. Hence, it was easier for the researcher to identify whether the students could be more conscious of their sentence variety while writing using the sentence variety checklist.

The first instrument employed in this study was the sentence variety checklist compiled from the content of Langan's book of College Writing Skills (1993) and the essay marking rubric adapted from the International English Language Testing System (IELTS) Writing Band Descriptor. The other instrument was a 20-item questionnaire to address research question 2 . The items in the questionnaire were based on the following 6 areas: i) increasing their awareness of what they write, ii) making their writing more interesting, iii) improving their lexical resources and grammatical accuracy, iv) producing writing with impact, v) promoting critical thinking in them, and vi) whether the checklist added limitations in the process of writing. The questionnaire is shown in Appendix 2.

The students were given a topic to write a 200 to 250-word opinion-based essay in week 5 of the 14-week intensive English program before going through the sentence variety checklist. The essays were collected for marking. In week 6, the teacher-researcher distributed the checklists to the students and went through each item emphasizing ways to write varieties of sentences. Follow-up practices on the items were also done after that for more understanding, and in week 7 the teacherresearcher instructed the students to write another essay of the same nature as the previous one on the same topic, but that one was guided by the sentence variety checklist to enhance varieties. The essays were then collected for marking, and results were then ready to be compared to the results of the first set of essays.

Immediately after handing in the second essays, the students were given the questionnaires on their perceptions of the usage of the sentence variety checklist as compared to the first time writing without the checklist. Fifteen minutes were allocated for them to respond to the questionnaires. Data to answer the first research question were obtained from the band score given to the essays, while the responses to the questionnaires were to address the second research question.

The data obtained were then analysed using a paired-samples t-test (repeated measures) to compare the students' writing bands before and after using the sentence variety checklist. According to Pallant (2013), this technique is used when we have a group of respondents and collect data from them from two different occasions or two different conditions. Frequency count was used for the data obtained for the other research question due to few number of respondents involved. 
INTERNATIONAL JOURNAL OF ACADEMIC RESEARCH IN BUSINESS AND SOCIAL SCIENCES

Vol. 9, No. 13, Special Issue: Revolutionizing Education: Challenges, Innovation, Collaboration., 2019, E-ISSN: 2222-6990 @ 2019 HRMARS

\section{Results and Discussions}

Research Question 1: Is there any difference in students' writing performance before and after using the Sentence Variety checklist?

Table 2: Paired Sample t-Test of Significant Difference in Students' Writing Performance Before and After Using the Sentence Variety Checklist

\begin{tabular}{|c|c|r|r|r|}
\hline & Mean & $\mathrm{N}$ & Std. Deviation & $\begin{array}{r}\text { Std. Error } \\
\text { Mean }\end{array}$ \\
\hline Pair $1 \mathrm{NOCL}$ & 3.900 & & & \\
& 0 & 20 & .78807 & .17622 \\
$\mathrm{CL}$ & $\begin{array}{l}4.450 \\
0\end{array}$ & 20 & .88704 & .19835 \\
\hline
\end{tabular}

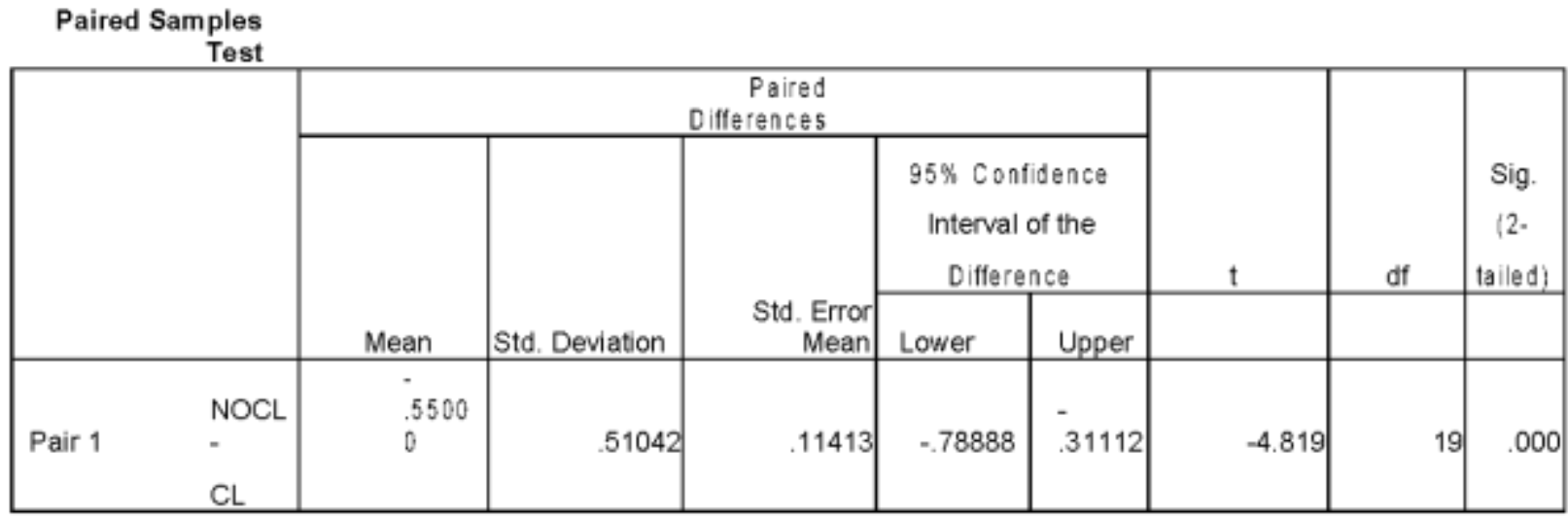

A paired-samples t-test was conducted to evaluate the impact of the intervention on students' writing performance by comparing the band scores given before and after the intervention. There was a statistically significant increase in the students' writing performance from the first writing $(\mathrm{M}=3.9, \mathrm{SD}=.79)$ to the second writing $(\mathrm{M}=4.45, \mathrm{SD}=.89), t(19)=-4.819$, with $\mathrm{p}<.00005$. These results suggest that the checklist does have an effect on students' writing performance. 
Research Question 2: What are students' perceptions towards the use of sentence variety checklist in writing?

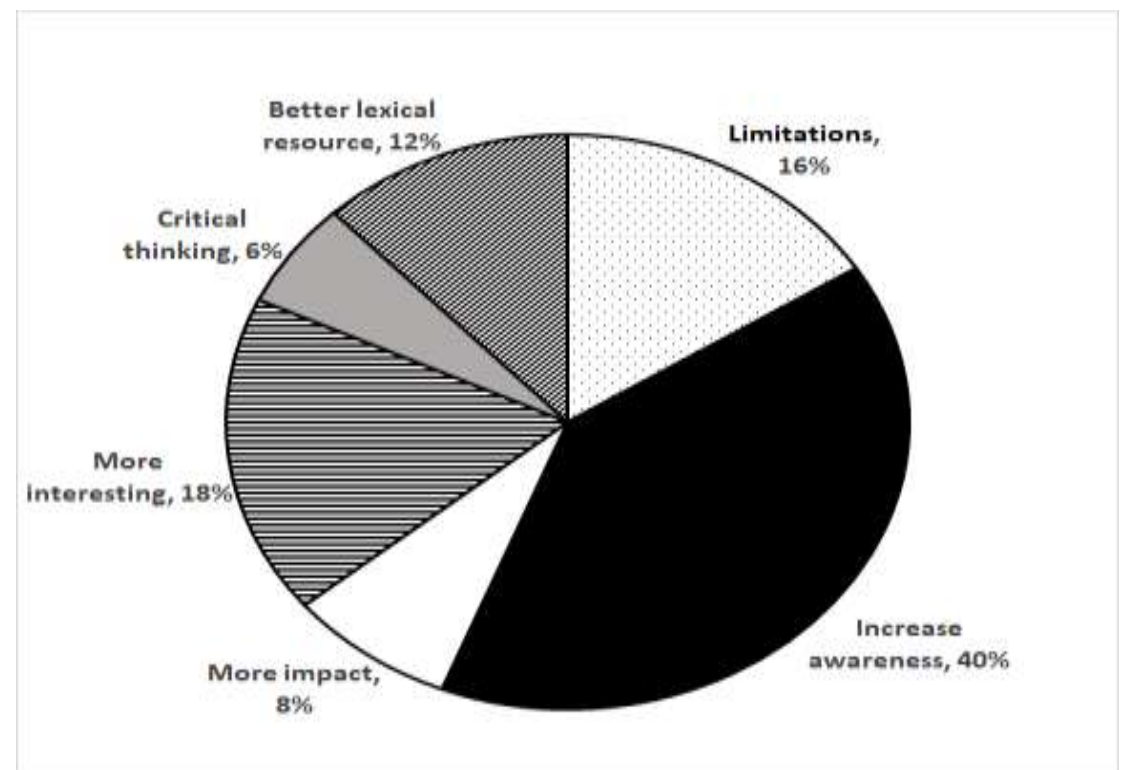

Figure 1. Students' Perceptions on Using Sentence Variety Checklist

Students' perceptions with regards to using the sentence variety checklist were based on the 20 items in the questionnaire that were then put into ranks from the highest to the lowest. The highest rank was dominated by the fact that the checklist increased the students' awareness (40\%) of what they put on paper and followed by making writing more interesting (18\%).

In spite of the two positive points that students agreed upon, they also felt that the sentence variety checklist somehow controlled their writing process in which it was mainly time and energy consuming which is labelled under limitations (16\%). In addition, the checklist was believed to help them in writing sentences with better lexical resources (12\%) namely in terms of word choice and transition signals. The lowest aspects in rank were more impact (8\%) and critical thinking (6\%).

Despite the slight difference in the essay scores, the sentence variety checklist has proven that it does promote students' writing performance. Students need to be prompted with the essential elements in writing and be able to apply them in writing. This is rather consistent with Biber (2001) when he emphasized that the writer who had more time to make grammatical choices used a greater variety of complex structures than the speaker who was under more stringent fluency constraints in real time. Content and organization are important but ability to apply them well in writing is equally crucial. This justifies Krashen's theory of language acquisition on the Acquisition-Learning Hypothesis which states that language learning is the product of formal instructions and incorporates a conscious process. This makes the students become more aware of knowledge about the language. Writing more and more essays continuously may not be able to help students in improving their writing if they are not well-guided on how to add more 'colours' in their writing. So, the intervention of the sentence variety checklist in the process of writing among ESL students should be taken objectively in order to further enhance their writing. 
With the higher bands obtained for their second essays, students indeed welcome the sentence variety checklist as a tool to assist them in writing. They strongly feel that the checklist managed to create awareness of what they have learned to be used in writing. This shows that they may have not been so aware of the importance in applying their knowledge of sentence patterns and a lot more prior to this. Apart from promoting awareness while writing, students also find that the checklist is able to make their writing more interesting for they were also guided to begin their sentences using other parts of speech, among other items suggested. This validates Krashen's Monitoring Hypothesis in second language acquisition because according to him, second language learners should monitor their utterances for instance, utilizing their understanding of learned grammar to edit and plan. Besides, it is also worth comparing these findings to one of the approaches from the theory of ESL writing by Silva (1990) which is the controlled approach. This approach states that writing is dominated by the controlled or guided approach which is influenced by structural analysis and behaviourist psychology. As it sees learning to write as an exercise in habit formation in which students are trained to practice sentence patterns and vocabulary by means of writing, it is imperative to make these students aware of what they should use and do based on what they have learned.

In addition, the results of this study also reveal that limitations could be the factors these students were experiencing while doing the writing. This may be due to the fact that the ESL students, in higher or lower levels of English proficiency classes were not used to doing this before, so they found that using the checklist may have slowed down their process of writing.

\section{Conclusion}

To conclude, this study which has examined whether sentence variety checklist developed based on the content of Langan's book, College Writing Skills (1993) could be an added instrument in enhancing ESL students' writing, and studied the perceptions of a group of students from an intensive English language program on the sentence variety checklist, has revealed that there is a difference in students' writing performance after using the sentence variety checklist with mixed perceptions from the students.

These findings, therefore imply that there is a need to carefully scrutinize students' writing performance for particular kinds of problems associated with sentence variety and also to extend or modify assessment and intervention practices to better understand the specific barriers to a student's writing performance. The emphasis of this scrutiny should fall on sentence structures that pose the greatest challenges to the development of writing. As stressed by Saddler (2007), the ability to create a variety of sentences that clearly express intended meaning and this ability can only be learned with direct instruction.

Finally, it is strongly recommended that sentence variety checklist be used across the curriculum to support ESL students' writing proficiency. In promoting sentence variety, educators should focus on creating better and more meaningful sentences, rather than spending so much time editing the work spelling mistakes or other technical problems. 
INTERNATIONAL JOURNAL OF ACADEMIC RESEARCH IN BUSINESS AND SOCIAL SCIENCES

Vol. 9, No. 13, Special Issue: Revolutionizing Education: Challenges, Innovation, Collaboration., 2019, E-ISSN: 2222-6990 @ 2019 HRMARS

\section{References}

Biber, D. (2001). Dimensions of variation among eighteenth century speech-based and written registers. Chapter 18 in Variation in English: Multi-Dimensional Studies. Routledge.

Clabough, C. (2014). Idiot's Guides: Creative Writing. Penguin (USA) Inc.

Congjun, M. (2005). A Taxonomy of ESL Writing Strategies. In proceedings: Redesigning Pedagogy: Research, Policy and Practice.

Krashen, S. (1985). Writing: Research, theory and applications. Oxford: Pergamon Institute of English.

Langan, J. (1993) College Writing Skills with Readings, 3rd Edition. McGraw Hill College, New York. National Commission on Writing (2003). The Neglected " $R$ ": The Need for a Writing Revolution, New York: College Board.

Pallant, J. (2013). SPSS Survival Manual. Retrieved from https://www.allenandunwin.com

Pedersen, L. P. (1977). Improving Syntactic and Semantic Fluency in the Writing of Language Arts Students through Extended Practice in Sentence Combining. University Microfilm International

Purdue OWL, Sentence Variety (2013) https://owl.english.purdue.edu/owl/resource/573/01

Saddler, B. (2007). Improving Sentence Writing Ability through Sentence-Combining Practice. ERIC Collection Search Education Resources.

Scott, C. M. \& Balthazar, C. (2013) The Role of Complex Sentence Knowledge in Children with Reading and Writing Difficulties. Perspectives on Language and Literacy. ProQuest.

Scott, C. M. \& Nelson, N. W. (2009) Sentence Combining. Assessment and Intervention Applications. Perspectives on Language Learning and Education. ProQuest.

Silva, T. (1997)Differences in ESL and Native-English-Speaker writing: The research and its implications. In C. Severino, J. Guena and J. Butler (eds.), Writing in multicultural settings. New York: Modern Language Association of America. 